\title{
Information technologies as a means of patriotic education of junior pupils
}

\author{
Galina Palatkina ${ }^{1}$, Zhanna Sorokina ${ }^{1 *}$, Alena Palatkina ${ }^{1}$, Sergei Popov ${ }^{2}$, and Galina \\ Galchenko ${ }^{2}$ \\ ${ }^{1}$ Astrakhan State University, 414056, Astrakhan, Russia \\ ${ }^{2}$ Don State Technical University, 344003, Rostov-on-Don, Russia
}

\begin{abstract}
The study examines the theoretical aspects of the patriotic education of primary schoolchildren in the context of the use of information technologies, defines the meaning and functions of information technologies in the educational process of school education. The patriotic upbringing of primary school students is more than relevant, since the preservation and revival of cultural heritage begins with a small homeland (family, courtyard, school, etc.) and is a key moment in the upbringing of the modern generation.In order to study the level of patriotic education of primary school students, we conducted a survey of schoolchildren, the results of which showed: most of them have a low level of patriotic education, which is due to the lack of due attention of the state as a whole and educational institutions in particular to the issue of patriotic education of schoolchildren.Thus, the problem of patriotic education of primary schoolchildren in the context of digitalization of education has acquired new relevance in connection with new views on the quality of upbringing and education of the younger generation.
\end{abstract}

\section{Introduction}

Since the inception of the educational system to this day, scientists have been looking for optimal organizational and pedagogical conditions for education that would correspond to the modern requirements of society.In connection with the implementation of the updated the Federal state educational standard of primary general education (approved by order of the Ministry of Education and Science of Russia dated October 6, 2009 No. 373, as amended by orders dated November 26, 2010 No. 1241, dated September 22, 2011 No. 2357) [1], as well as with the entry of Russia into the world educational system, the attention to the problem of pedagogical effectiveness of the use of information technology as a means of patriotic education of primary school students had beenincreased.

The Federal Law No. 273-FZ of December 29, 2012 (as amended on December 8, 2020) "On Education in the Russian Federation" [2], Federal State Educational Standard [1],Education development strategyin the Russian Federation for the period up to 2025 from May 29, 2015 N 996-r[3], pay special attention to the formation and development of a

\footnotetext{
* Corresponding author: zhanna1982_82@mail.ru
} 
personality with the qualities of a citizen - patriot of the Motherland, capable of successfully performing civil duties in peacetime and wartime.

Patriotism - it is the foundation of the basic elements of the national identity of the people, manifested in the feeling of love, pride and devotion to their homeland, its history, traditions, culture, in the understanding of their moral duty to it, in the readiness to protect its interests, as well as in the manifestation of tolerance towards others [4].

Scientists in the field of pedagogy and psychology $[5,6,7,8,9,10]$, etc.)had proved that patriotic education must be started even in preschool, early school age, since it is during that period the child identifies himself as a part of the micro and macro society in which he was born and raised; learns to love and respect himself, his family, school, yard, city, etc., learns to respect nature and the results of human activity.

Love for the Motherland is the result of the knowledge gained about it. The sources of this knowledge could be: a school lesson, excursion, observation, reading of works of art, conversation with adults. Many scientists believe that the use of information technology as a means of patriotic education of children of primary school age creates the most optimal conditions for the accumulation of impressions, the formation of ideas, the education of patriotic feelings in children. [11]

The regionalization of Russian education has become the starting point for the activation of innovative processes associated with the modernization of the content and technologies of education and upbringing, with the development and scientific substantiation of new means and methods of cultural identification of a child in the space of culture and society. One of the conditions for the patriotic education of juniorschoolchildren is the use of information technology in the work of an educational institution [12].

Despite the fact that the issues of using information technologies in the primary grades of general education schools are discussed in the theoretical provisions and studies of the methodological nature $[13,14,15]$, these studies mainly considered the use of information technologies in methodological work with teachers and in the process of document management of an educational institution.

In addition, in publications devoted to educational work, there are very few of those that consider the influence of information technology on the organization of patriotic education of primary school students.

Insufficient development of the problem determined the research topic; information technology as a means of patriotic education of junior pupils.

\section{Materials and Methods}

On the basis of secondary school No. 8, the city of Astrakhan, the diagnostics of the level of knowledge and pupil's understanding about the cultural, historical and natural values of the Astrakhan region and the city of Astrakhan as well as clarifying their relationship to these values junior schoolchildren was carried out. The study has involved pupils of the 3rd grade "B" in the number of 34 .

With the aim of determining the patriotic education level of junior schoolchildren, we have selected indicators proposed by D.Phil. in education science, professor I.F. Kharlamov, based on the psychological and pedagogical characteristics of a child of primary school age. These components are cognitive, behavioral and emotional.

The research methods used for the analysis: cluster analysis, content analysis, comparative analysis, interpretation. 


\section{Results and discussion}

After analyzing the results of primary school pupilsdiagnostics we have identified three levels of a sense of patriotism in junior pupils:

- the high level is characterized by affection and respect for oneself and others; shows concern for other people; strives for patriotic activity; interested in the history of his native land;

- the middle level: only under the control of an adult the moral qualities of the child, a sense of affection and respect for their family, home, school; a desire to care for others could be seen;

- the low level: sometimes shows a sense of affection and respect for his family, home, school; there is no desire to take care of other people; there is no desire to participate in patriotic events.

The study showed that only 4 students $(11 \%)$ have a high level of formation of patriotic feelings, 9 people $(26 \%)$ have an average level and 21 people $(63 \%)$ have a low level of formation of patriotic feelings (see Fig. 1).

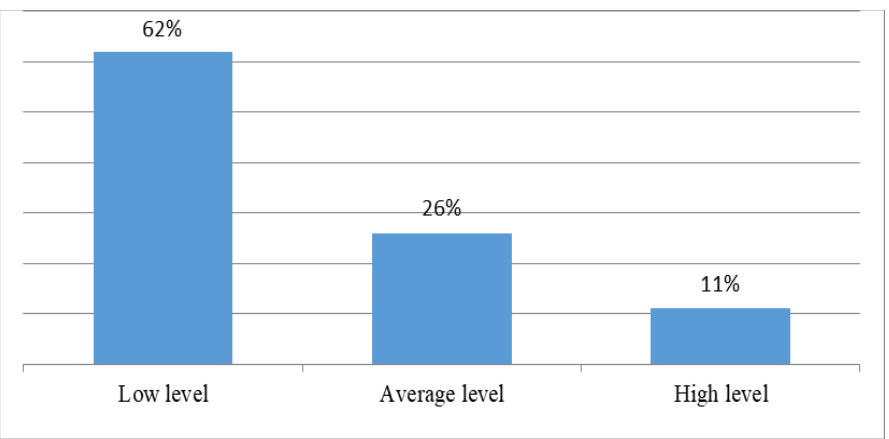

Fig.1. The patriotic education level of junior schoolchildren at the ascertaining stage of the experiment.

Low level patriotic education of junior school children is the result of insufficient attention on the part of the state to the problems of patriotic education of the younger generation, which in turn led to a weakening of the educational function of educational institutions.

The search for means of solving this issue led to the need to increase theeffectiveness of the educational process through the use of information technologies inthe patriotic education of primary schoolchildren.

To achieve the assigned tasks the project "About courage, heroism, glory" dedicated to the Defender of the Fatherland' Day has been realizedin the 3-rd grade B of secondary school No. 8, the city of Astrakhan.

The goal of the project is to foster a sense of patriotism in primary school'pupils through the integration of regional material, including the study of the history of their native land, virtual excursions, meetings with interesting people, visiting museums (museum of local lore, museum of military glory), memorial sites (Memorial complex "Eternal Flame", Astrakhan Kremlin, Monument to Peter the Great, etc.), located within the city and beyond, and information technology in the pedagogical process of the school (internet, computers, multimedia projector for presentations).

Information technology teaching is the set of methods and technical means of collecting, organizing, storing, processing, transmitting and presenting information that expands the knowledge of people and develops their ability to manage technical and social processes. The importance of information technology for pedagogy lies in the ability to develop the mental, 
creative abilities of primary school pupils, their ability to work independently with various sources of information in order to gain new knowledge.

The effectiveness of the patriotic education of junior schoolchildren depends on taking into account their age characteristics, which are expressed in concentration on the object for a short time, the frequent change of the type of activity. The main method of obtaining information remains play and visual material. Visibility and bright, positive emotions give junior pupils the opportunity to easily memorize and assimilate the material. Therefore, the use of the graphic, sound and interactive capabilities of the computer evokes in the child a number of positive emotions, aesthetic experiences, which in turn contribute to the formation of a spiritual and moral attitude towards patriotism, the acquisition of social and emotional experience.

After the formative experiment, we conducted a control experiment in order to determine the levelpatriotic education of junior schoolchildren... In the control experiment, we used the same techniques that were considered according to the same criteria as in the ascertaining experiment (see Fig. 2).

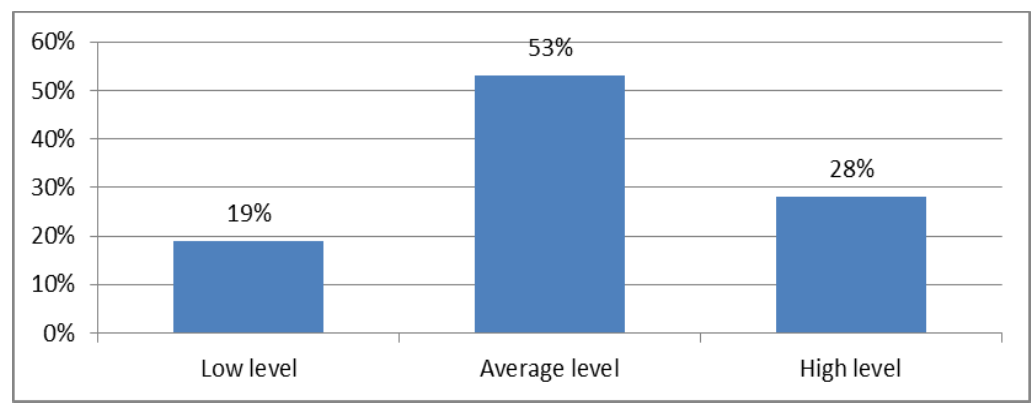

Fig. 2. The level of patriotic education of junior schoolchildren at the control stage of the experiment.

We see that at the control stage of our study, $28 \%$ of students had a high level of patriotic education of junior pupils, 53\% - with an average and 19\% - with a low level of patriotic education.

Based on the results obtained, changes were noted according to the three studied criteria. The following Table 1 gives the summary of theresults.

Table 1. Dynamics of the level of patriotic education of primary schoolchildren according to three criteria at the beginning and end of the experiment.

\begin{tabular}{|c|c|c|c|c|c|c|}
\hline $\begin{array}{c}\text { Formation } \\
\text { levels } \\
\text { indicators }\end{array}$ & $\begin{array}{r}\mathrm{H} \\
\text { le } \\
(\% \text { ofs } \\
\end{array}$ & $\begin{array}{l}\text { sh } \\
\text { el } \\
\text { Idents) }\end{array}$ & $\begin{array}{r}\text { N } \\
(\% 0 \\
\end{array}$ & $\begin{array}{l}\text { Idle } \\
\text { vel } \\
\text { udents) }\end{array}$ & (\% 0 & $\begin{array}{l}\text { ow } \\
\text { vel } \\
\text { tudents) }\end{array}$ \\
\hline \multicolumn{7}{|c|}{ Stages } \\
\hline & Const. & Counter. & Const. & Counter. & Konst & Counter \\
\hline \multicolumn{7}{|l|}{ Criteria } \\
\hline cognitive & 2 & 38 & 24 & 51 & 74 & eleven \\
\hline behavioral & 49 & 56 & 19 & 32 & 32 & 12 \\
\hline emotional & thirteen & 22 & 43 & 47 & 44 & 31 \\
\hline
\end{tabular}

In the process of analyzing the indicators of the cognitive component at the ascertaining stage of the experiment, the manifestation of a sense of patriotism in juniorschoolchildren, it turned out that the students' desire to do something for themselves prevails, which indicates a low level of its formation (74\% of schoolchildren). After the experiment, the level of knowledge increased in $63 \%$ of the students. 
After analyzing the results obtained at the control stage of the experiment, we came to the conclusion that the majority of students $(56 \%)$ have a stable positive awareness of their behavior, which is characteristic of a high level of formation of the behavioral component of patriotism. For $32 \%$ of schoolchildren with an average level of indicators formation patriotic education able to adequately perceive external circumstances, correctly assess oneself and the situation, leads to the right decisions, judgments, actions. $12 \%$ of students are at a low level of formation of the behavioral component of patriotism. This group of children is characterized by an unstable, negative awareness of behavior.

Analyzing the results of the emotional component of the feeling of patriotism, we came to the conclusion that $47 \%$ of schoolchildren have superficial ideas about their homeland, devoid of an emotional component. Pupils who have an idea of the Motherland, who love their home, family, for whom a patriot is not just a word, but a person endowed with certain moral qualities, rights and responsibilities, make up $22 \%$ of pupils.

For visual presentation of the results two diagrams were drawn (see Fig. 3, 4).

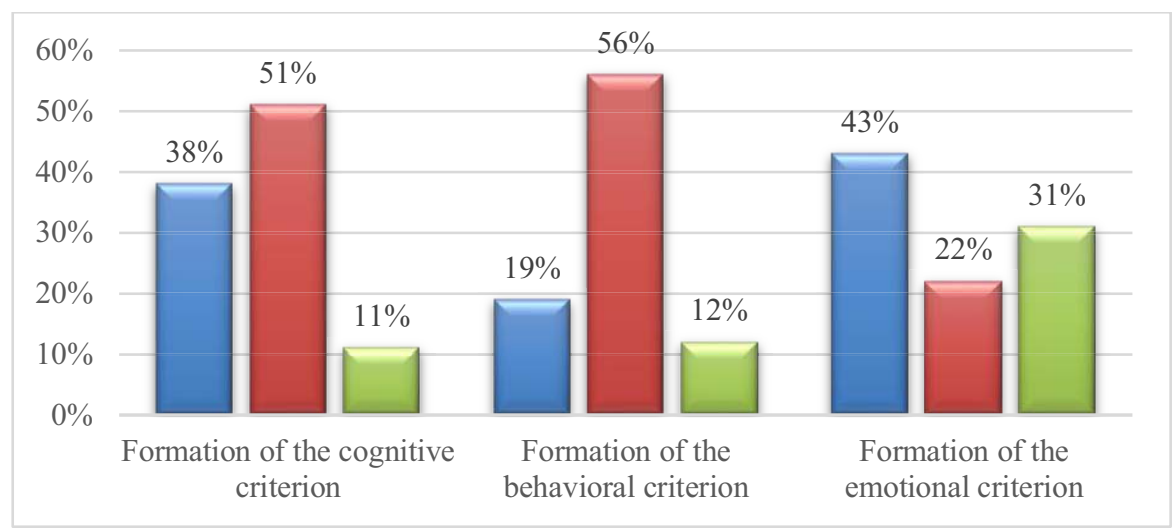

Fig. 3. The level of patriotic education of junior schoolchildren according to three criteria at the ascertaining stage of the experiment.

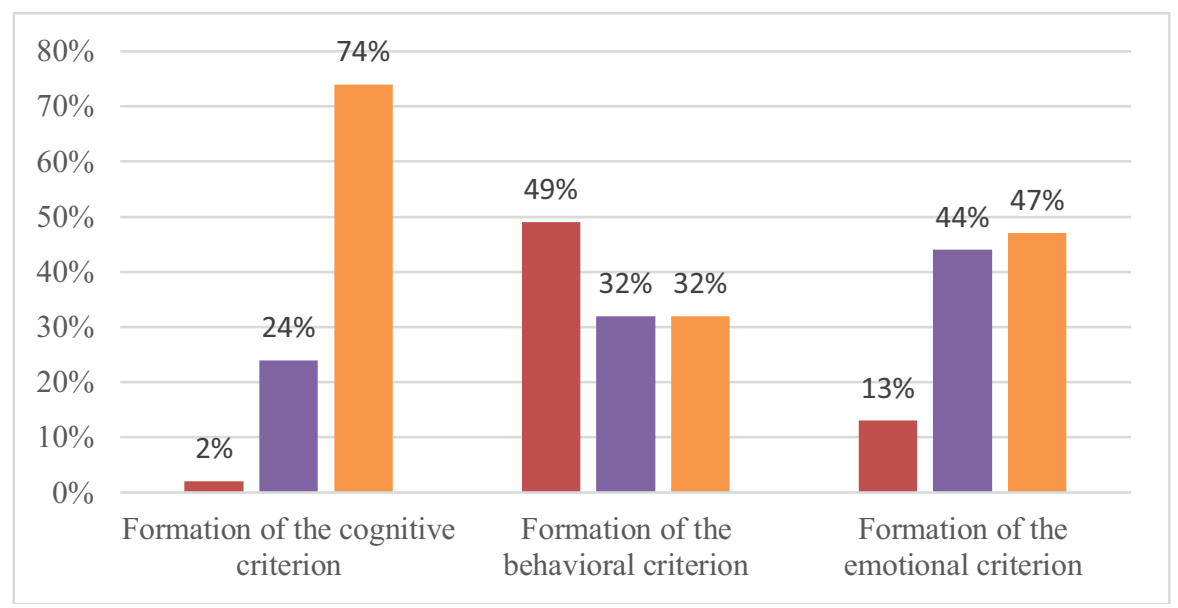

Fig. 4. The level of patriotic education of junior schoolchildren according to three criteria at the control stage of the experiment. 


\section{Conclusion}

The demands of society to the younger generation have become the starting point for the activation of innovative processes related to the modernization of content and education technologies, with the development and scientific justification of new means and ways of cultural identification of a child in the space of culture and society. One of the conditions for the patriotic education of younger students is the integration of regional material into the pedagogical process of the school, taking into account the age characteristics of the child.

The analysis of the experimental results, as well as the mathematical processing of these results, allowed us to quantitatively confirm the qualitative changes that have occurred in the patriotic education of primary schoolchildren due to the use of information technologies, namely: the level of knowledge of children about the cultural, historical and natural values of the Astrakhan region has increased; there are positive changes in the emotional attitude of children to the values of their native land; the majority of pupils have a stable positive awareness in their behavior, which is characteristic of a high level of patriotism formation.

At the same time, aspects of the problem under consideration were identified that require further research, in particular: the development of regional, socio-cultural and sociopedagogical models of patriotic education, creation of favorable material, technical and social conditions.

\section{References}

1. Federal state educational standards [Electronic resource]. URL: https://fgos.ru/ (date of access: 26.02.2021).

2. In the Federal Law of December 29, 2012 No. 273-FZ [Electronic resource]. URL: //http://www.consultant.ru.

3. Education development strategy in the Russian Federation for the period up to 2025 from May 29, 2015 N 996-r.

4. L.D. Gudkov, B.V. Dubin, Education Issues 3, 258-273 (2005).

5. A.N. Vyrshchikov, Patriotic education: methodological aspect (Volgograd, 2001).

6. Kh.A. Berdyaev, Self-knowledge (Kniga, Moscow, 1991).

7. A.A. Bodalev, Perception and understanding of man by man (Publishing house of Moscow State University, Moscow, 1982).

8. N.I. Ilyin, Formation of patriotic relations among students: Abstract of the thesis. ... diss..Cand. ped. Sciences (Tambov, 2003).

9. S.E. Matushkin, N.V. Ippolitova, Pedagogical research: hypotheses, projects, implementation 4 (2) (2011).

10. M.S. Kagan, Social and humanitarian knowledge 6 (2000).

11. L.E. Nikonova, Education of the beginnings of patriotism in older preschool children, Dis ... Cand. ped. Sciences (Moscow, 1989).

12. A.A. Antsiferova, Formation of ideas about the Motherland in the process of acquainting children with the life around them (Publishing house "Raduga", Ulyanovsk, 1973).

13. S.A. Ezopova, I.A. Kalabina, V.A. Novitskaya, Teacher of an additional educational institution 1, (2018).

14. E.A. Baronenko, Yu.A. Raisvikh, I.A. Korobchenko, Bulletin of the Chelyabinsk State Pedagogical University 3, (2019).

15. L.V. Shabaltina, L.Z. Fatkhullina, Vestnik USATU 14 (5) (40), (2010). 